\title{
Graham Patch Versus Modified Graham Patch in the Management of Perforated Duodenal Ulcer
}

\author{
Kidwai $\mathrm{R}^{1}$, Ansari $\mathrm{MA}^{2}$
}

\begin{abstract}
Introduction: Peptic ulcer perforation is a serious complication which affects $2-10 \%$ of peptic ulcer patients. It presents with an overall mortality of $10 \%$ although various authors had reported incidence between $1.3 \%$ and $20 \%$. Being a life threatening complication of peptic ulcer disease, it needs special attention with prompt resuscitation and appropriate surgical management if morbidity and mortality are to be contained. Aims and objectives: To compare outcome and complications in Graham patch and Modified Graham patch repair in perforated duodenal ulcer. Material and Methods: A prospective randomized controlled trial was conducted to compare the outcome and complication viz. leakage, obstruction after Graham's patch repair and modified Graham's patch repair undergoing duodenal ulcer perforation in various surgical units of Nepalgunj Medical College Teaching Hospital. Out of these 60 patients; one group (30 cases) underwent Graham's patch repair and another group (30 cases) underwent modified Graham's patch repair. The outcome of procedure was measured in terms of complication like leakage, obstruction and mortality. Results: Duodenal ulcer perforation in group A was more common in male; 58(96.66\%) patients were male 2 (3.33\%) were female $(\mathrm{M}: \mathrm{F}=29: 1)$. The mean age was 46.80 (SD 13.9) years. In Group B it was more common in male; $58(96.66 \%)$ patients were male 2(3.33\%) were female (M:F=29:1). The mean age was 48.60(SD 14.04) years. Incidence of complication was more common in Group $B$, no statistically significant difference was found between two groups. The incidence of post operative leakage was 1 (3.33\%) and in Group B were 2(6.70\%). The chi square test was used to compute the $p$ value using SPSS 19. The chi square $p$ value was calculated as 0.554. Hence there was no significant difference between the Group A and Group B. The incidence of burst abdomen was same $2(6.70 \%)$ in both the groups. Conclusion: The analysis of results of present study consisting of altogether 60 patients undergoing duodenal ulcer perforation repair showed that Graham's patch repair is as effective as modified Graham's patch repair in terms of morbidity and mortality. Hence there is no statistically significant difference in undergoing either procedure of repair. It is concluded that either procedure can be undertaken depending upon surgeon preference.
\end{abstract}

Key words: Burst abdomen, graham patch repair, leakage, modified graham patch repair, omental patch, peptic ulcer disease

\section{INTRODUCTION}

Peptic ulcer perforation is a serious complication which affects $2-10 \%$ of peptic ulcer patients. Peptic ulcer perforation presents with an overall mortality of $10 \%$ although various authors had reported incidence between $1.3 \%$ and $20 \%$. Being a life threatening complication of peptic ulcer disease, it needs special attention with prompt resuscitation and appropriate surgical management if morbidity and mortality are to be contained $^{1-5}$.

Perforation occurs when ulcer erodes through full thickness of stomach or duodenum. Perforation is most common complication of peptic ulcer. Bleeding ulcer and use of non steroidal anti inflammatory drugs (NSAID) and/or aspirin have been inextricably linked with perforated peptic ulcer disease

1. Dr. Roman Kidwai

2. Dr. Meraj Alam Ansari

Address for correspondence:

Dr. Roman Kidwai

Department of Surgery

Nepalgunj Medical College Teaching Hospital

Nepalgunj, Banke, Nepal

Email: romankidwai1@gmail.com
(PUD), especially in the elderly. More than $20 \%$ of patients over the age of 60 years presenting with a perforated ulcer are taking NSAIDs at the time of perforation ${ }^{6}$.

The most accepted method of surgical closure of the perforation is called Graham patch repair. In 1937, Roscoe Graham described this method. The perforated ulcer is identified either through the open incision. After laparotomy, packs are placed around the perforation to contain any further spill while the sutures are being placed and then the omental tongue is brought into position. Three or four sutures are used preferably of non absorbable material. If the needle is introduced, with care being taken to avoid the posterior duodenal mucosa and the needle is passed parallel to the anterior wall of duodenum, it is extremely unlikely that the posterior duodenal mucosa or wall would be incorporated into the sutures, which, of course, were it to occurs, would obstruct the duodenum.

Before sutures are tied, the adjacent omentum is brought up to the perforation with the sutures untied and laid out on the anterior surface of the duodenum, and are then successively tied from the superior to inferior side, so as to tampon the perforation with the vascularised omental pedicle graft. Care should be exercised to be sure that the suture are tied 
sufficiently snugly to hold the omentum in place, but the tension exerted by the tied suture on the omentum should be such that the blood supply to the omentum is not impaired. The patch must be a living omental patch, and the omentum should not be strangulated ${ }^{7}$.

This technique was later modified and called as Modified Graham patch repair (MGPR), in which the three or four sutures are placed as described above and are then tied to close the ulcer. The omental patch placed on the tied suture, and another set of knots are tied to hold the omentum in place over the duodenal perforation closure. There is concern that the omentum will not be as intimately applied to the duodenal perforation and may not represent as good a seal as is the case when the omentum is laid directly on the open ulcer bed ${ }^{8}$.

\section{MATERIAL AND METHODS}

This is a hospital based prospective comparative study conducted in Nepalgunj Medical College Teaching Hospital in the department of General Surgery from March 2013 to February 2014. All the patients of duodenal ulcer perforation were included except giant duodenal ulcers $>20 \mathrm{~mm}$ in diameter, posterior duodenal ulcers and sealed duodenal ulcer perforation. Total 60 patients were taken and divided in two groups. Each group consisted of 30 patients. Group A underwent Graham Patch repair and Group B underwent Modified Graham Patch repair. Their outcome were collected in preformed proforma and data so collected were subjected to SPSS 19 for analysis.

\section{RESULTS}

Most of the patients fall between $26-70$ years of age in both $A$ and $B$ groups being $93.33 \%$. The maximum number of patients in group $A$ were $11(36.7 \%)$ found in the age group of $41-55$ years. Similarly the maximum number of patients in group $B$ was $12(40 \%)$, found in the age group of $41-55$ years.

Sex distribution of the patients. In group $A$ there were $29(96.7 \%)$ males and $1(3.3 \%)$ females. In group B sex distribution was same as group $A$. In group $A$ it was present in $28(93.3 \%)$ patients and absent in only $2(6.7 \%)$ patients. In group B it was present in $22(73.3 \%)$ patients and absent in $8(26.7 \%)$ patients. The $p$ value from chi square test came out to be 0.038 which is significant.

There was $1(3.3 \%)$ leakage present in group $A$ whereas there were $2(6.7 \%)$ leakage in group $B$. The $p$ value from chi square test came out to be 0.554 which is not significant. In group $A$ and group B there were $2(6.7 \%)$ patients of burst abdomen present in each group. The $p$ value from chi square test came out to be 1.00 which is not significant.

\section{DISCUSSION}

In the present study a total of 60 patients were treated for acute perforated duodenal ulcer in our hospital over a period of one year. These were divided into 2 groups. Group A and Group B, each consisted of 30 patients. They underwent Graham patch repair and Modified Graham patch repair respectively.

1. Age: The commonest age at presentation was between 41

\begin{tabular}{|c|c|c|c|c|}
\hline \multirow{2}{*}{ Age Group } & \multicolumn{2}{|c|}{ Group A (n=30) } & \multicolumn{2}{c|}{ Group B (n=30) } \\
\cline { 2 - 5 } & No. of cases & Percent & 2 & No. of cases \\
\hline$<25$ Years & 2 & 6.70 & 3 & 23.30 \\
\hline $26-40$ Years & 9 & 30.0 & 12 & 40.00 \\
\hline $41-55$ Years & 11 & 36.70 & 6 & 20.00 \\
\hline $56-70$ Years & 7 & 23.30 & 3 & 10.00 \\
\hline$>70$ Years & 1 & 3.3 & 30 & 100 \\
\hline
\end{tabular}

Table I: Distribution of patients according to age

\begin{tabular}{|c|c|c|c|c|}
\hline \multirow{2}{*}{ Sex } & \multicolumn{2}{|c|}{ Group A (n=30) } & \multicolumn{2}{c|}{ Group B (n=30) } \\
\cline { 2 - 5 } & No. of cases & Percent & No. of cases & 9 \\
\hline Male & 29 & 96.70 & 1 & 96.70 \\
\hline Female & 1 & 3.30 & 30 & 3.30 \\
\hline Total & 30 & 100 & 300 \\
\hline
\end{tabular}

Table II: Distribution of patients according to sex 


\begin{tabular}{|c|c|c|c|c|}
\hline \multirow{2}{*}{ Presence of pus } & \multicolumn{2}{|c|}{ Group A (n=30) } & \multicolumn{2}{c|}{ Group B (n=30) } \\
\cline { 2 - 5 } & Frequency & Percent & Frequency & Percent \\
\hline Present & 28 & $93.3 \%$ & 22 & $73.3 \%$ \\
\hline Absent & 2 & $6.70 \%$ & 8 & $26.7 \%$ \\
\hline
\end{tabular}

Table III: Distribution of patients according to presence of pus in intraperitoneal cavity

\begin{tabular}{|c|c|c|c|c|}
\hline \multirow{2}{*}{ Leakage } & \multicolumn{2}{|c|}{ Group A (n=30) } & \multicolumn{2}{c|}{ Group B (n=30) } \\
\cline { 2 - 5 } & Frequency & Percent & Frequency & Percent \\
\hline Present & 1 & 3.30 & 2 & 6.70 \\
\hline Absent & 29 & 96.70 & 28 & 93.30 \\
\hline
\end{tabular}

Table IV: Distribution of patients according post operative leakage

\begin{tabular}{|c|c|c|c|c|}
\hline \multirow{2}{*}{ Burst Abdomen } & \multicolumn{2}{|c|}{ Group A (n=30) } & \multicolumn{2}{c|}{ Group B (n=30) } \\
\cline { 2 - 5 } & Frequency & Percent & Frequency & Percent \\
\hline Present & 2 & 6.70 & 2 & 6.70 \\
\hline Absent & 28 & 93.30 & 28 & 93.30 \\
\hline
\end{tabular}

Table V: Distribution of patients according burst abdomen

to 55 years with a mean age of 46.80 (SD 13.9) years which differs significantly from other reviews from Africa which had an average of 64.80 (SD 11.4) years ${ }^{9}$. Study conducted by Dakubo shows age ranged from 4-87 years with mean age of $40.90^{10}$. Guglieminotti described age varied from 20 to 65 years $^{11}$. This is consistent with other studies where mean age was 43.4, 35.3 (ranged 14 to 75 ), 37.53 and $45.49^{12-16}$ while Mehboob described mean age 31.4 years with peak incidence in $3^{\text {rd }}$ decade ${ }^{17}$.

2. Sex: In each group there were 29 males and 1 female. Male to female ratio was $29: 1,96 \%$ were male and $4 \%$ were female. Incidence of male was more as compared to study done by Plumer and Ohene in 2004 and 2006 respectively ${ }^{18}$. This can be explained on the basis of dietary habits and consumption of alcohol in this part of world.

3. Post operative leakage: Overall post operative complication in Graham patch and Modified Graham patch repair was low. Post operative leakage was 3.3\% and $6.7 \%$ respectively. The $p$ value from chi square test came out to 0.554 which is not significant. This was similar to the study done by Nuhu et al. in 2009 where only 4 post operative leakages were present in 55 patients undergoing emergency exploratory laparotomy. Besides, the major post operative complications in their study were post operative fever, wound and chest infection. The causes of these complications were multifactorial. These were delay in presentation, delay in surgical intervention, gross peritoneal soilage, septicemia and shock. The delay in surgical intervention, after the patient presents to hospital, is usually due to the time taken to resuscitate these very ill patients. The mortality rate of their study was $16.4 \%$ in compared to our study where there was no mortality. This may be explained by the differences in age composition of the patients and other risk factors of perforation. The deaths were due to septicaemia and electrolyte darangements ${ }^{19}$.

4. Burst abdomen: Similarly there was $6.7 \%$ burst abdomen in both the groups. The $p$ value from chi square test was 1.00 and 0.554 respectively which is not significant. Chalya et al. concluded in a retrospective and prospective study of clinical profile and outcome of surgical treatment of perforated peptic ulcers in Northwestern Tanzania: A tertiary hospital experience. Total 84 patients $(n=84)$ were included who had undergone Emergency Laparotomy with Graham's patch repair with omentopexy for duodenal ulcer perforation. Post operative complications were recorded in $25(29 \%)$ patients. Of these surgical sites infection was in $12(48 \%)$ patients, post operative pyrexia was in 9(36\%) patients, wound dehiscence and burst abdomen was in $5(20 \%)$ patients and incisional hernia in $2(8 \%)$ patients. Overall complications rate in their series were higher than our series. This difference in complication can be explained by differences in antibiotic 
coverage, meticulous preoperative care and proper resuscitation of the patients before operation, improved anaesthesia and somewhat better hospital environment ${ }^{20}$.

\section{CONCLUSION}

The analysis of results of present study consisting of altogether 60 patients undergoing duodenal ulcer perforation repair showed that Graham's patch repair is as effective as modified Graham's patch repair in terms of morbidity and mortality. Hence there is no statistically significant difference in undergoing either procedure of repair. It is concluded that either procedure can be undertaken depending upon surgeon preference.

\section{REFERENCES}

1. Testini $M$, Portincasa P, Piccinni $G$, et al. Significant factors associated with fatal outcome in emergency open surgery for perforated peptic ulcer. World J Gastroenterol. 2003;9:2338-40.

2. Soll AH. Peptic ulcer and its complications. In: Sleisinger \& Fordtran's Gastrointestinal and Liver Disease: Pathophysiology, Diagnosis, Management. $6^{\text {th }}$ ed. Edited by: Feldman M, Scharschmidt BF, Sleisenger MH, Philadelphia PA: W.B. Saunders; 1998:620-78.

3. Rajesh V, Sarathchandra S, Smile SR. Risk factors predicting operative mortality in perforated peptic ulcer disease. Trop Gastroenterol. 2003;24:148-50.

4. Hermansson M, Von Holstein CS, Zilling T. Surgical approach and prognostic factors after peptic ulcer perforation. Eur J Surg. 1999;165:566-72.

5. Elnagib E, Mahadi SE, Mohamed E, et al. Perforated peptic ulcer in Khartoum. Khartoum Medical Journal. 2008 1(2):62-4.

6. Gabriel SE, Jaakkimaine L, Bombardier C. Risk for serious gastrointestinal complication related to use of non steroidal antiinflammatory drugs-a meta-analysis. Ann Intern Med. 2006;115:787.

7. Graham RR. The treatment of perforated duodenal ulcers. Surg Gynecol Obstet. 1937; 64:235-8.

8. Lau WY, Leung $\mathrm{KH}$, Kwong $\mathrm{KH}$, et al. A randomized study comparing laparoscopic versus open repair of perforated duodenal ulcer using suture or sutureless technique. Ann Surg. 1996;224:131-8.

9. Ohene-Yeboah M, Togbe B. Perforated gastric and duodenal ulcers in an urban African population. West Afr J Med. 2006;25:205-11.

10. Manakuru SR.Current management of peptic ulcer perforations. Pak J Med Sci. 2004;20(2):157-63.

11. Guglieminotti P, Bini R, Fontana D, et al. Laparoscopic repair for perforated peptic ulcer with U-CLIP (R). World J Emerg Surg. 2009;29(4):28.

12. Arveen S, Jagdish S, Kadambari D. Perforated peptic ulcer in south India: An institutional perspective. World J Surg. 2009;32(8):1600-4.

13. Torab FC, Amer M, Abu-Zidan FM, et al. Perforated peptic ulcer: different ethnic, climatic and fasting risk factors for morbidity in Al-ain medical district, United Arab Emirates. Asian J Surg. 2009;32(2):95-101.

14. Bin-Talib AK, Razzaq RA, Al-Kathiri ZO. Management of perforated peptic ulcer in patients at a teaching hospital. Saudi Med J. 2008;29(2):245-50.

15. Balouch $\mathrm{Q}$. Analysis of peptic ulcer perforation cases at $\mathrm{CMC}$ teaching hospital ,Larkana. Pak J Surg. 2004;20(2):79-81.

16. Dakubo JC, Naaeder SB, Clegg Lumptey JN. Gastroduodenal peptic ulcer perforation. East Afr Med J. 2009;86(3):100-9.

17. Mehboob M, Khan JA, Saleem SM, et al. Peptic duodenal perforation: An audit. J Coll Physcians Surg Pak. 2000;10(f):1013.

18. Plummer JM, McFarlane ME, Newnham. Surgical managementof perforated duodenal ulcer: the changing scene. West Indian Med J. 2004;53:378-81.

19. Nuhu. Acute perforated duodenal ulcer in Maiduguri. The internet journal of surgery. 2009;21:1.

20. Chalya. Clinical profile and outcome of surgical treatment of perforated peptic ulcers in Northwestern Tanzania: A tertiary hospital experience. World journal of emergency surgery. 2011;6:31. 